\title{
IDENTIFICATION OF KEY PARAMETERS AFFECTING ENERGY CONSUMPTION OF AN AIR HANDLING UNIT
}

\author{
David Goodman \\ Ali Razban \\ Indiana University-Purdue \\ University Indianapolis \\ Indianapolis, Indiana, USA
}

Indiana University-Purdue University Indianapolis Indianapolis, Indiana, USA

\author{
Jie Chen \\ Indiana University-Purdue University Indianapolis \\ Indianapolis, Indiana, USA
}

Jing Li

Indiana University-Purdue

University Indianapolis

Indianapolis, Indiana, USA

This is the author's manuscript of the article published in final edited form as:

Goodman, D., Chen, J., Razban, A., \& Li, J. (2016, November). Identification of Key Parameters Affecting Energy 


\section{ABSTRACT}

Air handling unit system (AHU) is one of the series of mechanical systems that regulate and circulate the air through the ducts inside the buildings. In a commercial setting, air handling units accounted for more than $50 \%$ of the total energy cost of the building in 2013. The energy efficiency of the system depends on multiple factors. The set points of discharge air temperature and supply air static pressure are important ones. ASHRAE Standard 90.1-2010 requires multi-zone HVAC systems to implement supply air temperature reset. Energy is wasted if the set points are set constant. However, the waste has never been quantified. The objectives of this study were to (1) develop and validate a mathematical model, which can be used to predict the system performance in response to various controls, specifically the set-point control strategies, and associated energy consumption, and (2) to recommend measures for optimizing the AHU performance by optimizing the setting schedules .

In this research, a gray box model was established to evaluate the performance of an AHU. Individual components were modeled using energy and mass balance governing equations that represent the inherent physical processes and interactions with other components. Engineering Equation Solver (EES) was selected for system simulation due to its capabilities of finding the solutions of a large set of complicated equations. The model was validated using two sets of sub hourly real time data. The model performance was evaluated employing Mean Absolute Percentage Error (MAPE) and Root Mean Square Deviation (RMSD). The model was used to create the baseline of energy consumption with constant set points and predict the energy savings using two different reset schedules.

The AHU, which serves the entire basement of a campus building on IUPUI campus, was used for this study. It normally has constant set points of discharge air temperature and supply air static pressure. The AHU was monitored using sensors. The data were filtered and transferred to a Building Automation system. Operation information and design specifications of the AHU were collected. Two reset schedules were investigated to determine the better control strategy to minimize energy consumption of the AHU. Discharge air temperature was reset based on return air temperature (RA-T) with a linear reset schedule from March 4 to March 7. Static pressure of the supply air was reset based on the widest open Variable Air Volume (VAV) box damper position from March 20 to March 23. Additionally, uncertainty propagation method was used to identify the dominant parameters affecting the energy consumption.

Results indicated that $17 \%$ energy savings was achieved using discharge air temperature reset while the energy consumption reduced by $7 \%$ using static pressure reset. The results also indicated that outside air temperature, supply airflow rate and return air temperature were the key parameters that impact the overall energy consumption.

Keywords: HVAC, AHU, discharge air temperature reset, static pressure reset, energy, energy savings.

\section{INTRODUCTION}

Residential and commercial buildings account for $41 \%$ of total energy consumption [1] and 39\% of carbon dioxide (CO2) emissions in the United States [2]. Heating, Ventilation and Air-conditioning (HVAC) systems are the largest energy consumer, accounting for $32 \%$ of total building energy use [3]. Thus, it is essential to improve the energy efficiency of HVAC systems to reduce energy usage and minimize the effects on environment. While there are potential energy saving opportunities for each element of the HVAC system, this study will focus on optimizing control strategy with respect to the set points of discharge air temperature and supply air static pressure.

\section{BACKGROUND}

A few studies have been conducted with regards to the reset schedules. Wang et al. [4] presents that significant energy savings were achieved by optimizing the supply air temperature in a variable air volume system in different climates. A steady state energy consumption model of a single zone VAV AHU system was developed in Zhou et al. [5]. The supply air temperature was optimized using analytical optimization method to minimize the energy usage during economizer operation. In this study, estimated $90 \%$ energy was saved under specific space loads and outside air condition. However, the simulated results and control sequence were not validated through experiments.

Additionally for static pressure reset control strategy, Liu et al. [6] presented that fan power consumption and thermal energy consumption including both heating and cooling decreased with static pressure reset strategy. Housholder et al. employed Proportional plus Integral (PI) control loops and Tier and Respond static pressure reset strategies at the Energy Resource Station to make a comparison on the energy savings [7]. Housholder et al. implemented the strategy that led to the most substantial energy savings on the 
Lowe State University campus [7]. The test results demonstrated that the tiered Trim and Respond reset strategy contributed to 37\% fan energy savings per week.

Above studies provide good indications that reset schedules could reduce energy consumption of HVAC systems. However, the studies did not draw a comparison of the energy savings using different reset strategies. Additionally, no models were developed in the studies to predict the potential energy savings.

Modeling is the key in predicting system operation and performance. Three types of analytical approaches, known as white box, black box and gray box approach, have been widely used for HVAC systems modeling [8]. Black box model is data driven and mainly used for fault detection of an existing system. The generalization capability of a black box model is relatively low without knowing the system details. White box model is physics-based and primarily adopted for optimal design. However, due to complexity of HVAC systems, it is not practical to establish a reliable model in a reasonable time employing the white box modeling technique. Gray box modeling is a combination of both. The system configuration is not entirely known for gray box model. However, a number of parameters can be estimated based on the relationship between inputs and outputs. The relationship is obtained through the system and experimental data [8]. Gray box method is a combination of physical and non-physical approaches. Primarily, a physical model is developed to illustrate the system configuration and underlying process. And then key variables that have a substantial influence on system performance are identified [9].

Gray box approach has an advantage over the other two approaches due to its accurate prediction of system output and respectively high generalization capability by utilizing both physics equations and field measured data [10]. This approach can also be potentially used in fault detection and diagnosis (FDD) [9]. Thus, gray box modeling technique was adopted in this research.

The goal is to increase the AHU's energy efficiency. Our approach is to study the effects of different control strategies on energy saving through modeling. The objectives of this study were to (1) develop and validate a mathematical model, which can be used to predict the system performance in response to various controls, specifically the set-point control strategies, and associated energy consumption, and (2) to recommend measures for optimizing the AHU performance by optimizing the setting schedules.

\section{TEST FACILITY}

The air handling unit (AHU) used in this study was in the basement of the Engineering Technology building on the campus of IUPUI. The area was remodeled in 2006. The total square footage of the basement is 31,957 square feet. The primary use of the basement is classroom space; it also includes labs, general study areas and a mechanical room as shown in Figure 1.

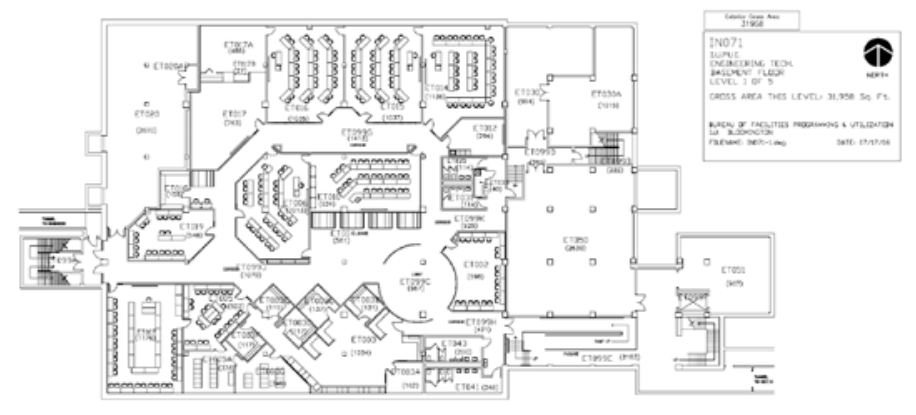

Figure 1: Floor Plan

The AHU is located in the basement mechanical room. Specific design parameters are listed in Table 1.

Table 1 AHU Design Specifications

\begin{tabular}{|l|l|l|}
\hline Component & Specifications \\
\hline \multirow{3}{*}{$\begin{array}{l}\text { Preheat } \\
\text { Coil }\end{array}$} & Surface Area: & 40 sq. ft. \\
\cline { 2 - 3 } & Rows: & 1 \\
\cline { 2 - 3 } & MBH (Mega BTU per hour) & 733 \\
\hline \multirow{2}{*}{\begin{tabular}{c} 
Cooling \\
\cline { 2 - 3 }
\end{tabular}} & Surface Area: & 40 sq. ft. \\
\cline { 2 - 3 } & Rows: & 6 \\
\hline
\end{tabular}




\begin{tabular}{|l|l|l|}
\hline \multirow{3}{*}{ Supply Fan } & MBH (Mega BTU per hour) & 796 \\
\cline { 2 - 3 } & Min OA CFM: & 5,000 \\
\cline { 2 - 3 } & Supply CFM: & 17,000 \\
\cline { 2 - 3 } & Horsepower: & 25 \\
\cline { 2 - 3 } External Static Pressure & 3 in. WC \\
\hline \multirow{3}{*}{ Return Fan } & Supply CFM: & 17,000 \\
\cline { 2 - 3 } & Horsepower: & 15 \\
\cline { 2 - 3 } & External Static Pressure & 1.75 in. WC \\
\hline
\end{tabular}

It is managed by the automation system made by Johnson Control, called Metasys building management system. This software has an online version through the Metasys Launcher application, which can be reached and connected from anywhere using internet and specific IP settings. Metasys allows the user to view various system settings and sensor functioning with their current properties. Metasys also has the functionality to work with field controller to perform some operator commands on the system. In the current research, Metasys system was used to collect system performance data and to implement the discharge air temperature (DA-T) reset and the static air pressure (SP) reset control strategies.

\section{MODELING}

Sensors and flow stations had already been installed on the AHU to monitor the various parameters. The data was then filtered and transferred to a Building Automation System (BAS) called Metasys. Specific inputs and outputs were selected for model simulation based on referenced studies and ASHRAE standards [9-15]. In addition, operation information and design specifications of the AHU were gathered from Campus Facility Staff at this stage.

The AHU, see figure 2, consists of a supply fan, a return fan, a cooling coil, a preheat coil and terminal units. Individual component was modeled using energy and mass balance governing equations that represent the inherent physical processes and interactions with other components. Engineering Equation Solver (EES) was selected for system simulation due to its capabilities of finding the solutions of a large set of complicated equations. EES is allowed to import thermodynamic and transport properties from REFPROP. It is also able to solve engineering problems associated with other programs using dynamic data exchange [15].

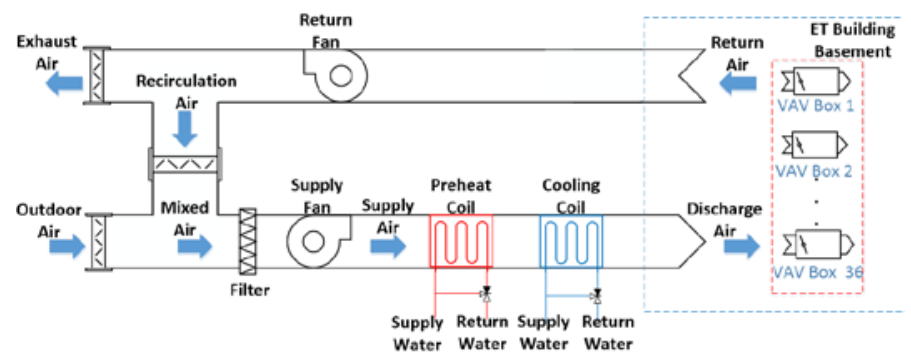

Figure 2: AHU Schematic Diagram

Five major energy consumption AHU components, see Figure 3 blocks, including supply fan, return fan, preheat coil, cooling coil and reheat coils, were modeled. Supply fan and return fan consume electricity. Cooling coil uses purchased chilled water while preheat coil and reheat coils utilize purchased hot water. 


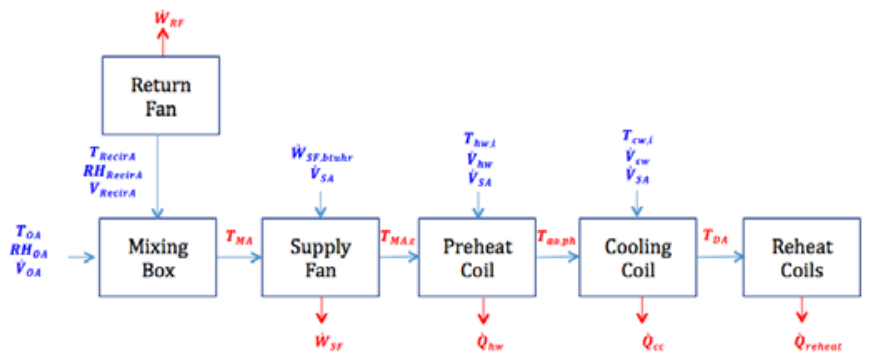

Figure 3: Major Energy Consumers of HVAC System

Chilled water pump and hot water pump were not taken into consideration in the model because the chillers and boilers were not accessible. Humidifiers were not included since they had been abandoned from the system. When supply air is distributed to the terminal units through air ducts, there is heat exchange between the conditioned air and surrounding environment. The heat losses were neglected in the model. Mixed air damper control, cooling coil valve control and preheat coil valve control using Proportional Integral Derivative (PID) controllers were not developed in the mathematical model due to the scope of the project.

Individual HVAC components were developed as a subprogram in EES. Subprogram could be viewed and modified as a standalone program that was able to be called from the main EES program. Subprograms were much more manageable and well-defined compared to a complex integrated program. Once a subprogram was verified and validated, it could be utilized in a wide variety of applications.

The inputs and outputs of the AHU model are shown in Figure 3. Most of the inputs for each HVAC component were imported from BAS. Three outside air temperature sensors are installed at different locations on campus to measure the outside dry bulb temperature. The average of the measured three outside air temperatures was utilized by BAS. Outside air relative humidity input was not available in BAS due to the lack of humidity sensor. Thus, the information was gathered from weather.com website for modeling use. The outside air relative humidity collected from weather.com was on an hour-to-hour basis while the sampling interval for BAS was 10 minutes. In order to keep the inputs consistent, the hourly recorded outside air relative humidity from weather.com was divided into 6 segments with a 10 minute time window as an input for the mathematical model. Due to space limitation, we will not discuss the gray-box model algorithms in this paper.

\section{Mixing box model}

A portion of the return air stream and the outside air stream are mixed together in the mixing chamber of the AHU. The mixed air is delivered via draw-through supply fan to be conditioned. As shown in Figure 4, the mixing box consists of three sets of dampers: exhaust air damper, outside air damper and return air damper.

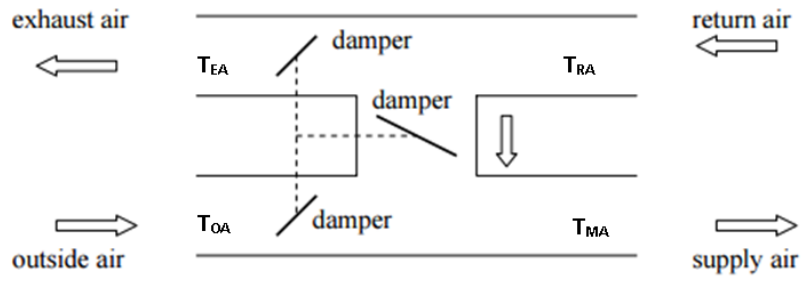

Figure 4: Mixing Box Schematic Diagram [16]

An Economizer is integrated in the AHU to provide free cooling, or to assist mechanical cooling when the outside temperature is low. When the outside air has a lower temperature (or enthalpy) than the supply air set point and cooling is called for, the economizer will be in operation mode by modulating the outside air damper from its minimum position to maximum position. The return air damper is adjusted from its maximum position to minimum position. When the outside air temperature is below or equal to $45^{\circ} \mathrm{F}$, the outside air damper is maintained at its minimum position to limit the energy waste to heat up the cold outside air while still meet indoor air quality requirements. When the outside air temperature is above or equal to $65^{\circ} \mathrm{F}$, the outside air damper is adjusted to its minimum 
position to prevent an increase in cooling load by incorrectly taking in the hot and humid outside air. Exhaust air damper regulates the amount of exhaust air to balance out the static pressure, control moisture and remove contaminants.

The mass and energy balances can be written as equation 1 and 2 respectively [9, 17]:

$$
\begin{aligned}
& \mathrm{V}^{*} \text { oaXoa }+\mathrm{V}^{*} \text { raXra }-\mathrm{V}^{*} \text { eaXea }=\mathrm{V}^{*} \text { saXma } \\
& V^{*} \text { oapoahoa }+ \text { V'raprahra }-V^{*} \text { eapeahea }=V^{*} \text { sapmahma }
\end{aligned}
$$

Figure 5 illustrates the variables used in the logic model and where the data was measured and stored. The model inputs are from BAS and weather.com website. The output, mixed air temperature, is calculated using the individual model developed in EES.

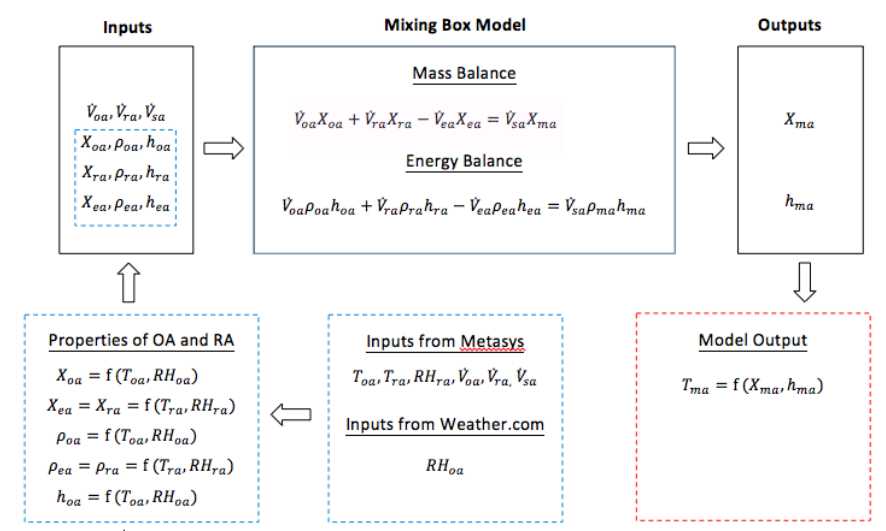

Figure 5: Mixing Box Model Logic

\section{Supply Fan Model}

Variable frequency drive (VFD) allows the supply fan motor to run at different speeds to adjust the amount of supply air. A pressure sensor is placed at the $2 / 3$ down-stream of the main duct to measure the supply air static pressure. VFD is controlled to maintain a constant supply air pressure set point of 1.80 inches WC. Supply fan power consumption is a function of static pressure, supply air flow rate and overall efficiency of fan and motor system [9]. Overall efficiency relates to fan shaft efficiency, motor efficiency, efficiency of mechanical transmission, and efficiency of control equipment [18].

Supply fan was sized on a design day basis. However, the supply fan runs in part load condition most of time. ASHRAE part load fan model was used to predict the energy use of the supply fan. In Salimifard et al.'s paper, a comparison of the actual supply fan power usage to simulated fan power consumption using ASHRAE 90.1 standard part formula and Energy plus formula was made [19]. The paper indicated that the accuracy of the prediction strongly depends on the actual part load curve in a specific building. Both part load models were used for the preliminary study. The equations 3 and 4 were used for supply fan power calculation because of its high accuracy, comparatively [19].

$$
\operatorname{PLR}_{\text {sf }}=\mathrm{V}^{*}{ }_{\mathrm{sa}} / \mathrm{V}^{*}{ }_{\text {sf,design }}
$$

Where PLR $_{\text {sf }}$ is part load ratio of supply fan operation (actual CFM/design CFM),

$$
\mathrm{W}_{\mathrm{sf}}^{\cdot}=\left(0.0013+0.147 \mathrm{PLR}_{\mathrm{sf}}+0.9506 \mathrm{PLR}_{\mathrm{sf}}^{2}-0.998 \mathrm{PLR}_{\mathrm{sf}}^{3}\right) \cdot \mathrm{BHP}_{\mathrm{SF}}
$$

Where $\mathrm{W}^{*}$ sf is supply fan power and BHP ${ }_{\mathrm{SF}}$ is supply fan motor horsepower.

\section{Temperature rise across supply fan model}

Fan and motor system add heat to the mixed air stream due to fan and motor heat and drive losses. The temperature rise across the supply fan section needs to be considered when calculating the cooling load. 
The temperature rise was calculated using the equations from AHU manufacturer product data [20].

$$
\mathrm{W}^{\cdot}{ }_{\mathrm{SF}, \mathrm{btuhr}}=1.1 * \mathrm{~V}_{\mathrm{SA}}{ }_{\mathrm{SA}} * \Delta \mathrm{T}_{\mathrm{SF}}
$$

Where $\mathrm{W}^{\cdot}{ }_{\mathrm{SF}, \mathrm{btuhr}}$ is the supply fan motor power output, $\mathrm{V}_{\mathrm{SA}}{ }_{\mathrm{SA}}$ is the supply air flow rate, and $\Delta \mathrm{T}_{\mathrm{SF}}$ is the temperature rise across the supply fan section.

\section{Return Fan Model}

The equations 6 and 7 were used for return fan power calculations [19].

$$
\mathrm{PLR}_{\mathrm{rf}}=\mathrm{V}_{\mathrm{ra}}^{\cdot} / \mathrm{V}_{\mathrm{rf}, \mathrm{design}}
$$

Where PLR $\mathrm{R}_{\mathrm{rf}}$ is part load ratio of return fan operation (actual CFM/design CFM).

$$
\mathrm{W}_{\mathrm{rf}}^{\cdot}=\left(0.0013+0.147 \mathrm{PLR}_{\mathrm{rf}}+0.9506 \mathrm{PLR}_{\mathrm{rf}}^{2}-0.998 \mathrm{PLR}_{\mathrm{rf}}^{3}\right) \cdot \mathrm{BHP}_{\mathrm{RF}}
$$

Where $\mathrm{W}^{*}{ }_{\mathrm{rf}}$ is return fan power and $\mathrm{BHP}_{\mathrm{RF}}$ is return fan motor horsepower.

\section{Preheat Coil Model}

The function of the preheat coil is to prevent cold air from freezing the cooling coil. When the mixed air temperature is below $50^{\circ} \mathrm{F}$, the preheat coil valve is open to heat up the entering mixed air temperature. The schematic diagram of the preheat coil is displayed in Figure 6.

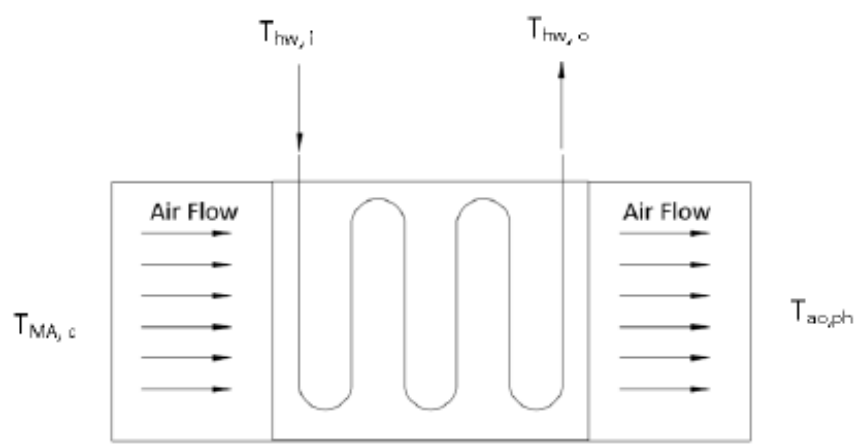

Figure 6: Schematic Diagram of the Pre-heat Coil

The preheat coil model is based on the model developed by Zajic [21]. In order to simplify the model, a few assumptions have been made:

- The heat transfer between the air and the hot water is in a steady state at a 10 minutes interval. Transient effects are neglected for the air.

- The leaving hot water temperature is assumed to be identical to the mean hot water temperature.

- Latent heat is not taken into consideration. The coil is analyzed as dry coil.

- Constant heat transfer coefficients are used for calculations.

The energy balance on the water side of the coil:

$$
\frac{T_{h w, o}}{t_{\text {interval }}}=\frac{1}{c} \cdot\left[\rho_{h w} \cdot \dot{V}_{h w} \cdot c_{p, h w} \cdot\left(T_{h w, i}-T_{h w, o}\right)-\frac{U A_{h w}}{C F_{\min , h r}} \cdot\left(T_{h w, o}-T_{a o, p h}\right)\right]
$$

The energy balance on the air side of the coil:

$$
\frac{T_{a o, p h}}{t_{\text {interval }}}=\frac{1}{c_{p, m a, c}} \cdot\left[\frac{U A_{h w}}{C F_{\min , h r}} \cdot\left(T_{h w, o}-T_{a o, p h}\right)-\rho_{m a, c} \cdot \dot{V}_{S A} \cdot c_{p, m a, c} \cdot\left(T_{a o, p h}-T_{m a, c}\right)\right]
$$


The overall thermal capacity is $\mathrm{c}_{\mathrm{p} \text {,ma,c }}, \mathrm{UA}_{\mathrm{hw}}$ is the overall heat transfer coefficient, $\mathrm{t}_{\text {interval }}$ is the sampling interval and $\mathrm{CF}_{\text {min.hr }}$ is the conversation factor (converting minute to hour). $\mathrm{c}_{\mathrm{p}, \mathrm{ma}, \mathrm{c}}$ is estimated as $0.09 \mathrm{Btu} /{ }^{\circ} \mathrm{F}$. The heat transfer surface of the preheat coil is 40 square feet. Overall heat transfer coefficient per square feet is estimated as $50 \mathrm{Btu} / \mathrm{hr}^{-} \mathrm{ft}^{2}-^{\circ} \mathrm{F}[22]$. Thus, UA $\mathrm{Am}$ is $1000 \mathrm{Btu} / \mathrm{hr}-{ }^{\circ} \mathrm{F}$.

Theoretically, valve water flow is a function of pressure drop across the loop including the valve and coil, valve open position, the inherent valve characteristics, flow coefficients and valve authority [23, 24]. The valve open position can be read from BAS. However, differential pressure across the coil and valve is unknown. Installed valve characteristics are infeasible to estimate without manufacturer data. Therefore, a linear relationship between the valve open position and water flow rate is adopted in the mathematical model. Thus the preheat coil energy consumption at 10 minutes interval equation is:

$$
\mathrm{Q}_{\mathrm{hw}}=\rho_{\mathrm{ma}, \mathrm{c}} \square * \mathrm{~V}_{\mathrm{SA}}^{*} * \mathrm{c}_{\mathrm{p}, \mathrm{ma}, \mathrm{c}} *\left(\mathrm{~T}_{\mathrm{ao}, \mathrm{ph}}-\mathrm{T}_{\mathrm{ma}, \mathrm{c}}\right) * \mathrm{t}_{\text {interval }}
$$

\section{Cooling Coil Model}

Figure 7 shows the schematic diagram of the cooling coil. The supply air temperature was set at $55^{\circ} \mathrm{F}$. When supply air temperature is greater than supply air temperature set point, the cooling coil valve is modulated to cool down supply air temperature to its set point.

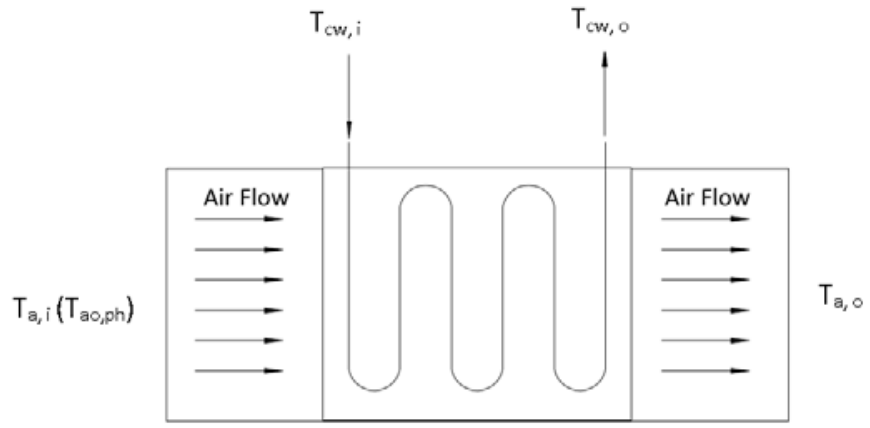

Figure 7: Schematic Diagram of Cooling Coil

The cooling coil model is also based on the model developed by Zajic et al. [21]. The assumptions for preheat coil model apply to cooling coil model as well. The energy balance equation on the water side of the coil is:

$$
\frac{T_{c w, o}}{t_{\text {interval }}}=\frac{1}{c} \cdot\left[\rho_{c w} \cdot \dot{V}_{c w} \cdot c_{p, c w} \cdot\left(T_{c w, i}-T_{c w, o}\right)-\frac{U A_{c c}}{C F_{\text {min }, h r}} \cdot\left(T_{c w, o}-T_{a, o}\right)\right]
$$

The energy balance equation on the air side of the coil is:

$$
\frac{T_{a o}}{t_{\text {interval }}}=\frac{1}{c_{p, m a, c}} \cdot\left[\frac{U A_{c c}}{C F_{\min , h r}} \cdot\left(T_{c w, o}-T_{a, o}\right)-\rho_{\text {ma }, c} \cdot \dot{V}_{S A} \cdot c_{p, m a, c} \cdot\left(T_{a, o}-T_{a, i}\right)\right]
$$

The heat transfer surface of the preheat coil is 40 square feet. Overall heat transfer coefficient per square feet is estimated as 15 $\mathrm{Btu} / \mathrm{hr}-\mathrm{ft}^{2}-^{\circ} \mathrm{F}[22]$. Thus, the overall heat transfer coefficient is $600 \mathrm{Btu} / \mathrm{hr}-{ }^{\circ} \mathrm{F}$.

Cooling energy consumption is a function of supply air flow rate, supply air density, and temperature difference between supply air and discharge air. Cooling coil energy consumption at 10 minutes interval is:

$$
\mathrm{Q}_{\mathrm{cc}}=\rho_{\mathrm{ao}, \mathrm{ph}} \square * \mathrm{~V}^{*}{ }_{\mathrm{SA}} * \mathrm{c}_{\mathrm{ao}, \mathrm{ph}} *\left(\mathrm{~T}_{\mathrm{ao}, \mathrm{ph}}-\mathrm{T}_{\mathrm{DA}}\right) * \mathrm{t}_{\text {interval }}
$$

Where $\mathrm{T}_{\mathrm{DA}}$ is discharge air temperature, which is the same as Ta,i.

\section{Zone Model}


The variable air volume (VAV) system controls the zone temperature by modulating the air flow while maintaining the constant supply air temperature set point. The targeted AHU serves 36 VAV terminal boxes throughout the ET basement. The damper position of the individual terminal unit varies to meet the desired room temperature. Reheat coil is included in the VAV box to heat the entering supply air in order to meet the local zone temperature set point. The components of a VAV box are shown in Figure 8.

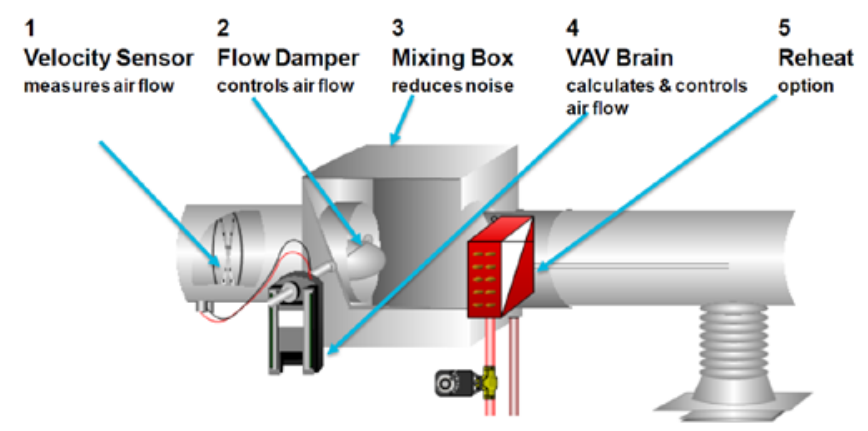

Figure 8: Components of a VAV Box [31]

In order to simplify the calculations, 36 VAV boxes were considered as a single VAV box. Reheat coil energy consumption at 10 minutes interval is:

$$
\mathrm{Q}_{\text {reheat }}=\rho_{\mathrm{DA}} * \mathrm{~V}_{\mathrm{SA}} *\left(\mathrm{~h}_{\mathrm{RA}}-\mathrm{h}_{\mathrm{DA}}\right) * t_{\text {interval }}(1
$$

Next, the mathematical model needed to be validated after it was developed. Model validation played an essential role to ensure the reliabilities of the AHU system model in terms of energy performance predictions. Two weekly data sets obtained in a week in February and March respectively were used in this validation. The simulated outputs and energy consumption of each component were compared with measured data and energy usage using real time data as inputs. Mean Absolute Percentage Error (MAPE) and Root Mean Square Deviation (RMSD) for individual components were evaluated to illustrate model performance.

Finally, uncertainly analysis was performed to pinpoint the parameters that had significant influence in energy consumption. The key parameters could be controlled and optimized to reduce the overall energy consumption and energy costs for future study.

\section{RESULTS}

Mean Absolute Percentage Error (MAPE) and Root Mean Square Deviation (RMSD) have been employed to measure the accuracy of the mathematical model. Both MAPE and RMSD are widely used to measure the average magnitude of the errors. Table 2 displays the error differences comparison for each component model using different data sets. Generally speaking, model prediction using the second data set was more accurate except for the supply fan model. The outdoor air temperature was higher from March 1 to March 31, which might contribute to the level of accuracy.

Table 2: Error Difference Comparison for Individual Models

\begin{tabular}{|c|c|c|c|c|}
\hline \multirow{2}{*}{ Parameter } & \multicolumn{2}{|c|}{$\begin{array}{c}\mathbf{2} / \mathbf{1} / \mathbf{2 0 1 5}-\mathbf{2} / \mathbf{2 8} / \mathbf{2 0 1 5} \\
\text { Avg. OAT 20 F }\end{array}$} & \multicolumn{2}{c|}{$\begin{array}{c}\text { 3/1/2015-3/31/2015 } \\
\text { Avg. OAT 40 F }\end{array}$} \\
\cline { 2 - 5 } & MAPE & RMSD & MAPE & RMSD \\
\hline MA-T & $6.85 \%$ & 5.27 & $3.61 \%$ & 2.4 \\
\hline W_SF & $11.99 \%$ & 0.58 & $34.63 \%$ & 1.25 \\
\hline W_RF & $49.39 \%$ & 0.19 & $12.76 \%$ & 0.3 \\
\hline PH-T & $12.95 \%$ & 8.22 & $2.01 \%$ & 1.66 \\
\hline DA-T & $12.66 \%$ & 8.03 & $2.23 \%$ & 2.22 \\
\hline
\end{tabular}

In order to compare model results, a baseline energy consumption study was performed. Energy consumption of each element was calculated using the first data set from February 25 to February 28. All the individual components were integrated to calculate the overall energy consumption. The overall energy consumption was the baseline case without using any reset control strategies. The details are shown in Table 3. 
Table 3: Baseline Energy Consumption

\begin{tabular}{|l|r|}
\hline Q reheat (BTU) & $9,633,080$ \\
\hline Q cooling (BTU) & 0 \\
\hline Q heating (BTU) & 130,893 \\
\hline E Supply Fan (BTU) & $1,242,296$ \\
\hline E Return Fan (BTU) & 420,964 \\
\hline Q total (BTU) & $11,427,233$ \\
\hline
\end{tabular}

In the baseline case, discharge air temperature was set at $55^{\circ} \mathrm{F}$ and supply air static pressure was set at 1.80 inch WC. In order to improve energy efficiency, discharge air temperature reset and supply air static pressure reset control strategies were applied. In cooling mode, increasing discharge air temperature reduces mechanical cooling energy and also terminal reheat. However, fan speed increases with a raise in discharge air temperature in order to compensate.

Supply air static pressure should be maintained just as high as it is required to satisfy the zone that needs most energy. The supply air static pressure and discharge air temperature reset control strategies interact with each other to compete for capacity control. Therefore, individual reset control strategies were evaluated separately.

The DA-T reset logic is based on direct proportional relation of RA-T input span of $70^{\circ} \mathrm{F}$ to $73^{\circ} \mathrm{F}$ and a DA-T output of $64^{\circ} \mathrm{F}$ to $56^{\circ} \mathrm{F}$. The linear correlation between DA-T and RA-T is shown in Figure 9. When there is an increase in RA-T, DA-T set point decreases incrementally based on the DA-T reset algorithm.

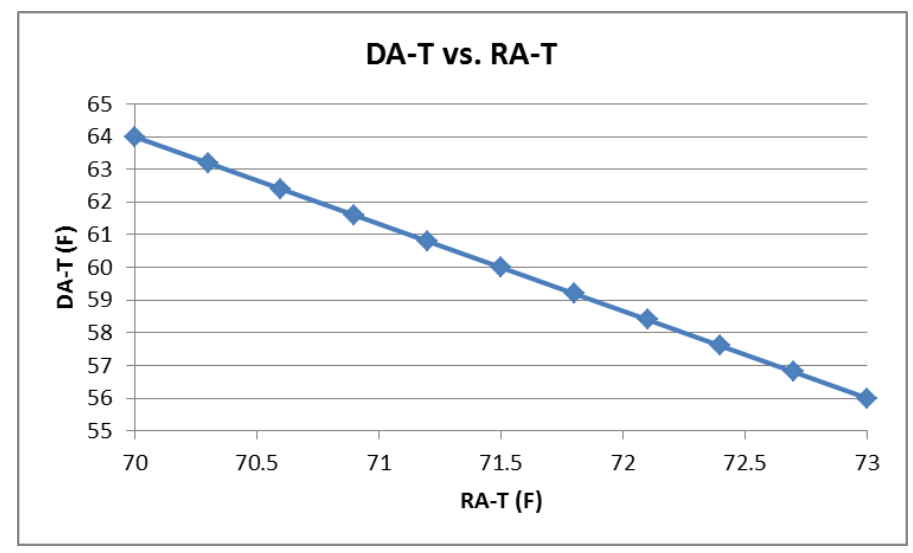

Figure 9: Correlation between DA-T and RA-T in DA-T Reset Logic

According to ASHRAE 90.1-2010, for systems with DDC of individual zone boxes reporting to the central control panel, static pressure set point shall be reset based on the zone requiring the most pressure; i.e., the set point is reset lower until one zone damper is nearly wide open [14].

Supply fan speed command was determined by the supply air static pressure. The speed was varied to maintain the set point of 1.80 inch WC. The static pressure was measured at $2 / 3$ of the supply air ductwork. The AHU was running a high supply air static set point because of an initial problem satisfying the cooling needs of a server room. They now have an additional cooling supplied by an air conditioner.

Supply air static pressure reset control logic was applied to reduce energy consumption. The control logic relationship is displayed in Figure 10. If one zone damper is greater than $90 \%$ then increase static pressure set point proportionally from the minimum of 0.8 inch WC to the previous maximum of 1.80 inch WC incrementally based on the damper range of $90 \%$ to $100 \%$. 


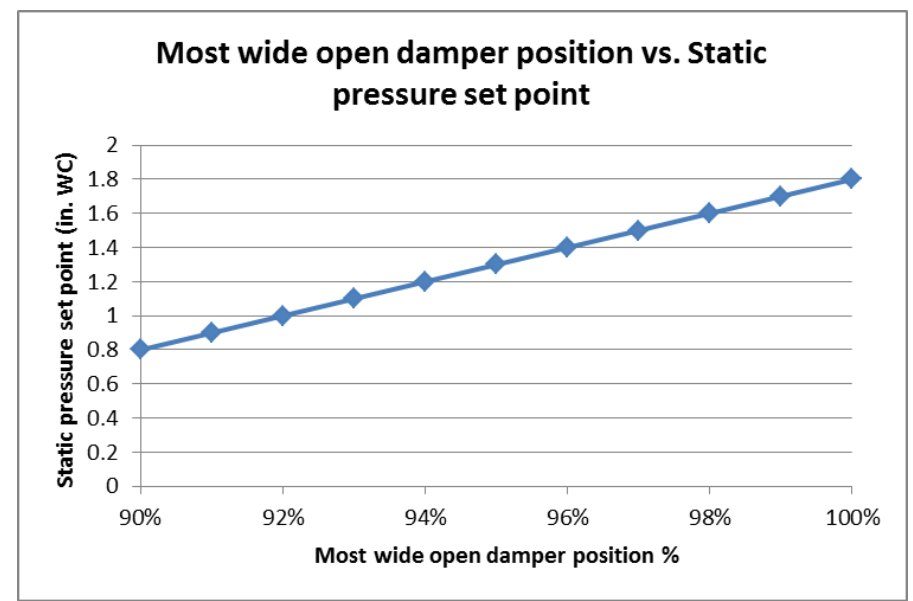

Figure 10: Static Pressure Reset

At this point, we can compare the baseline energy consumption case with the reset control strategies. Data was collected from March 4 to March 7 when the discharge air temperature reset (control strategy 1) was applied. Data was collected from March 20 to March 23 when the static pressure reset (control strategy 2) was applied. Description of the data sets is shown in Table 4.

Table 4: Description of Data Sets for Energy Consumption Comparison

\begin{tabular}{|c|c|c|c|c|c|}
\hline $\begin{array}{c}\text { Data } \\
\text { Set } \\
\text { No. }\end{array}$ & $\begin{array}{c}\text { Time } \\
\text { Period }\end{array}$ & $\begin{array}{c}\text { Sampling } \\
\text { Time }\end{array}$ & $\begin{array}{c}\text { Number } \\
\text { of } \\
\text { Samples }\end{array}$ & $\begin{array}{c}\text { Average } \\
\text { OA-T }\end{array}$ & $\begin{array}{c}\text { Aver } \\
\text { age } \\
\text { OA- } \\
\text { RH }\end{array}$ \\
\hline $\mathbf{1}$ & $2 / 25 /$ & 3.5 days & 500 & $22^{\circ} \mathrm{F}$ & $65 \%$ \\
& $2015-$ \\
& $2 / 28 /$ & & & & \\
& 2015 & & & & \\
\hline $\mathbf{2}$ & $3 / 4 /$ & 3.5 days & 500 & $27^{\circ} \mathrm{F}$ & $68 \%$ \\
& $2015-$ & & & & \\
& $3 / 7$ & & & & \\
\hline 3 & $3 / 2015$ & & & & \\
& $2015-$ & 3.5 days & 500 & $45^{\circ} \mathrm{F}$ & $62 \%$ \\
& $3 / 23 /$ & & & & \\
& 2015 & & & & \\
\hline
\end{tabular}

Table 5 demonstrates that when the system utilized DA-T reset control strategy, the total energy consumption reduced by $17.2 \%$. Individually, reheat energy consumption decreased by $25.5 \%$ and heating coil energy consumption decreased by $100 \%$. However, the fully closed preheat coil valve resulted from the higher outdoor air temperature but not the reset supply air temperature, therefore both supply fan and return fan power went up to compensate the decreased temperature difference.

When the system utilized supply air SP reset control strategy, the total energy consumption reduced by $7 \%$. In particular, reheat energy consumption went down $8.3 \%$. Cooling energy increased because an increase in outdoor air temperature drove the cooling coil valve open. Supply fan power consumption decreased by $1.3 \%$ while return fan power consumption decreased by $2.1 \%$.

Outside conditions were different when applied DA-T reset schedule and static pressure reset schedule, which might have an impact in the energy savings. When outside air temperature was between $45^{\circ} \mathrm{F}$ and $65^{\circ} \mathrm{F}$, the unit was in economizer operation, which caused the mixed air damper to modulate from minimum position to maximum position to provide free cooling. Thus the supply fan and return fan ran faster to deliver more air. 
Table 5: Energy Consumption Comparison between Baseline and Control Strategies

\begin{tabular}{|l|c|c|c|c|c|}
\hline & \multicolumn{2}{|l|}{$\begin{array}{l}\text { Baseli } \\
\text { ne }\end{array}$} & \multicolumn{2}{|l|}{$\begin{array}{l}\text { Control } \\
\text { Strategy 1 }\end{array}$} & \multicolumn{2}{l|}{$\begin{array}{l}\text { Control } \\
\text { Strategy 2 }\end{array}$} \\
\cline { 2 - 6 } & $\begin{array}{l}\text { No } \\
\text { Reset }\end{array}$ & $\begin{array}{l}\text { DA-T } \\
\text { Reset }\end{array}$ & $\begin{array}{l}\text { Energy } \\
\text { Saved }\end{array}$ & $\begin{array}{l}\text { SP } \\
\text { Reset }\end{array}$ & $\begin{array}{l}\text { Energy } \\
\text { Saved }\end{array}$ \\
\hline $\begin{array}{l}\text { Q_reheat } \\
\text { (BTU) }\end{array}$ & $9.63 \mathrm{M}$ & $7.17 \mathrm{M}$ & $2.46 \mathrm{M}$ & $8.83 \mathrm{M}$ & $801 \mathrm{k}$ \\
\hline $\begin{array}{l}\text { Q_cooling } \\
\text { (BTU) }\end{array}$ & 0 & 0 & 0 & $144 \mathrm{k}$ & $-144 \mathrm{k}$ \\
\hline $\begin{array}{l}\text { Q_heating } \\
\text { (BTU) }\end{array}$ & $131 \mathrm{k}$ & 0 & $131 \mathrm{k}$ & $11.1 \mathrm{k}$ & $119 \mathrm{k}$ \\
\hline $\begin{array}{l}\text { E_Supply } \\
\text { Fan } \\
\text { (BTU) }\end{array}$ & $1.24 \mathrm{M}$ & $1.69 \mathrm{M}$ & $-451 \mathrm{k}$ & $1.22 \mathrm{M}$ & $16.8 \mathrm{k}$ \\
\hline $\begin{array}{l}\text { E_Return } \\
\text { Fan } \\
\text { (BTU) }\end{array}$ & $421 \mathrm{k}$ & $597 \mathrm{k}$ & $-176 \mathrm{k}$ & $412 \mathrm{k}$ & $8.7 \mathrm{k}$ \\
\hline $\begin{array}{l}\text { Q_total } \\
\text { (BTU) }\end{array}$ & $11.4 \mathrm{M}$ & $9.46 \mathrm{M}$ & $1.96 \mathrm{M}$ & $10.6 \mathrm{M}$ & $802 \mathrm{k}$ \\
\hline
\end{tabular}

\section{CONCLUSION AND RECOMMENDATIONS}

At the AHU level, an individual components model was established using energy and mass balance governing equations. The theoretical model was validated with two sets of real time data. The deviations of simulated results from measured data were identified through MAPE and RMSE.

The predicted outputs of mixing box model tended to have a lower accuracy when the ambient temperature was low. The possible reason could be that the outdoor air temperature sensor was not calibrated and it did not function well when operated in low temperature range. The second data set from March 1st to March 31st proved that the deviations from the measured data were much lower when the outdoor air temperature was above $40^{\circ} \mathrm{F}$. The model performance of pre-heat coil and cooling coil were impacted by the accuracy of mixed air temperature since the mixed air temperature was a critical input to both pre-heat coil and cooling coil models.

The deviations of the fan models from measured data were greater compared to the other component models. The model performance of the fans varied significantly depending on how the fans are set up in a specific building. There is no one standard equation that is able to precisely predict the fan power consumption without knowing the actual fan performance curves.

The impact of input variables was identified in uncertainty propagation using RSS method. Outside air temperature, outside air flow rate and return air temperature were the most influential parameters in minimizing energy consumption.

Supply air static pressure reset and discharge air temperature reset strategies were performed to minimize the energy consumption. $17.2 \%$ energy savings was achieved using discharge air temperature reset while the energy consumption reduced by $7 \%$ using static pressure reset. The theoretical model could be used by facilities to predict potential energy savings when adopting a wide variety of measures under different operating conditions. It would allow facility managers to quantify and measure the improvements.

\section{ACKNOWLEDGMENTS}

This work was partially supported by the U.S. Department of Energy (DE-FOA-0000490). Facility access/assistance provided by Campus Facility Services via John Kamman II and Tom Pennington is greatly appreciated.

\section{REFERENCES}

[1] Energy Information Administration. U.S. energy consumption. 2014.

[2] US Department of Energy. Building Energy Data Book. 2006. 
[3] Energy Information Administration. EIA Annual Energy Outlook. 2008.

[4] Gang Wang and Li Song. Air Handling Unit Supply Air Temperature Optimal Control During Economizer Cycles. Energy and Buildings, 49:310\{316, 2012.

[5] John Q Zhou and David E Claridge. Pi Tuning and Robustness Analysis For Air Handler Discharge Air Temperature Control. Energy and Buildings, 44:1\{6, 2012.

[6] Mingsheng Liu, Jingjuan Feng, Zhan Wang, Lixia Wu, Keke Zheng, and Xiufeng Pang. Impacts of Static Pressure Reset on VAV System Air Leakage, Fan Power and Thermal Energy Part 1: Theoretical Model and Simulation. 2011.

[7] Brian Wayne Housholder. A Study on Static Pressure Reset and Instability in Variable Air Volume HVAC Systems. 2011.

[8] Abdul Afram and Farrokh Janabi-Shari. Review of Modeling Methods for HVAC Systems. Applied Thermal Engineering, 67(1):507\{519, 2014.

[9] ASHRAE Handbook-Fundamentals. American Society of Heating, Refrigerating and Air-conditioning Engineers. Inc., NE Atlanta, GA, 30329, 2009.

[10] Abdul Afram and Farrokh Janabi-Sharifi. Gray-box modeling and validation of residential hvac system for control system design. Applied Energy, 137:134\{150, 2015.

[11] Andrew Kusiak, Fan Tang, and Guanglin Xu. Multi-objective Optimization of HVAC System with an Evolutionary Computation Algorithm. Energy, 36(5):2440\{2449, 2011.

[12] Bourhan Tashtoush, M Molhim, and M Al-Rousan. Dynamic Model of an HVAC System for Control Analysis. Energy, 30(10):1729\{1745, 2005.

[13] Tobias Maile, Martin Fischer, and Vladimir Bazjanac. Building Energy Performance Simulation Tools: A Life-Cycle and Interoperable Perspective. Center for Integrated Facility Engineering (CIFE) Working Paper, 107:1 149, 2007.

[14] Pengfei Li, Yaoyu Li, John E Seem, Hongtao Qiao, Xiao Li, and Jon Winkler. Recent Advances in Dynamic Modeling of HVAC Equipment Part 2: Modelica-based Modeling. HVAC\&R Research, 20(1):150\{161, 2014.

[15] SA Klein and FL Alvarado. EES Manual. Middleton, Wisconsin, USA, 1999.

[16] Commissioning HVAC. Mixing box. 2006.

[17] Timothy Mulumba, Afshin Afshari, Ke Yan, Wen Shen, and Leslie K Norford. Robust Model-Based Fault Diagnosis for Air Handling Units. Energy and Buildings, 86:698\{707, 2015.

[18] Kees van Haperen. Recommendations for Calculations of Energy Consumption for Air Handling Units. EUROVENT, 2005.

[19] Parichehr Salimifard, Payam Delgoshaei, Ke Xu, and James D Freihaut. Comparison of Actual Supply Air Fan Performance Data to ASHRAE 90.1 Standard-2010 and DOE Commercial Reference Buildings Part Load Fan Energy Use Formula. ASHRAE/IBPSA-USA Building Simulation Conference, 2014.

[20] Carrier Corporation. Product Data. 2006.

[21] I Zajic, Tomasz Larkowski, Malgorzata Sumislawska, Keith J Burnham, and D Hill. Modelling of an Air Handling Unit: a Hammerstein-Bilinear Model Identification Approach. In Systems Engineering (ICSEng), 2011 21st International Conference on, pages 59\{63. IEEE, 2011.

[22] Heat Transfer Coefficients. 2015.

[23] Li Song, A Swamy, and G Shim. Feasibility Study of Developing a Virtual Chilled Water Flow Meter at Air Handling Unit Level. 2011.

[24] Atul Swamy, PE Li Song PhD, and PE Gang Wang PhD. A Virtual Chilled-Water Flow Meter Development at Air Handling Unit Level. ASHRAE Transactions, 118:1013, 2012. 